\title{
DANDO VOZ à VOZ DO POVO
}

Recebido: 15/01/2021

Aprovado: $21 / 06 / 2021$

DOI: $10.18817 /$ rlj.v5i01.2464

Publicado: $30 / 07 / 2021$

Mylena Frazão da Cruz ${ }^{1}$
Orcid ID: https://orcid.org/0000-0003-4580-4750

PIOVEZANI, Carlos. A voz do povo: uma longa história de discriminações. Petrópolis, RJ: Vozes, 2020.

Carlos Piovezani é professor associado do Departamento de Letras e do Programa de Pós-Graduação em Linguística da Universidade Federal de São Carlos (UFSCar). É também coorganizador de conhecidas obras para os que pesquisam em Análise do Discurso, sobretudo a de vertente francesa, como Legados de Michel Pêcheux (Editora Contexto); Presenças de Foucault na Análise do Discurso (Edufscar); Discurso, Semiologia e História (Editora Claraluz), entre outras.

A voz do povo: uma longa história de discriminações, sua segunda obra solo², foi publicada pela Editora Vozes, no corrente ano. O Prefácio é de Jean-Jacques Courtine, professor emérito da Sorbonne Nouvelle/Universidade de Paris III, e a Apresentação de Marc Angenot, professor emérito da McGill University. A obra dividese em três capítulos: Ouvir a voz do povo (com quatro seções); Breve genealogia da voz e escuta populares (com duas seções) e Retratos de um porta-voz popular na mídia brasileira (com quatro seções). Ademais, o autor nos apresenta uma Introdução e encerra a obra com o epílogo intitulado Por uma metalinguagem da emancipação popular. Suas referências estão dispostas ao longo da obra em notas de rodapé.

No Prefácio, Courtine afirma que com $A$ voz do povo, Piovezani "[...] nos mostra como a fala popular foi objeto de discriminações insistentes ao longo da história do

\footnotetext{
1 Licenciada em Letras com habilitação em língua portuguesa e em língua espanhola, e suas respectivas literaturas, pela Universidade Federal do Maranhão (UFMA). Foi bolsista por dois anos do Programa Institucional de Bolsas de Iniciação Científica (PIBIC), com pesquisa financiada pelo Conselho Nacional de Desenvolvimento Científico e Tecnológico (CNPq), tendo como objeto de pesquisa a mulher ludovicense de meados do século XIX e as práticas discursivas que a mídia da época produziu sobre ela. Tal pesquisa culminou no seu trabalho de conclusão de curso. Atualmente, é mestranda da L2 - Estudos de Linguagem e Práticas Discursivas, do Programa de Pós-Graduação em Letras, da Universidade Federal do Maranhão (PGLetras - UFMA), tendo como objeto de estudo a constituição do sujeito mulher/esposa na pós-modernidade. É membro do Grupo de Pesquisa em Linguagem e Discurso do Maranhão (GPELD - UFMA).E-mail: mylena.mfc@gmail.com

${ }^{2}$ A primeira obra solo do autor se intitula Verbo, corpo e voz e foi publicada em 2009, pela Editora UNESP.
} 
Ocidente e nos mostra também que esses preconceitos são produtos e reflexos das desigualdades sociais e das dominações políticas [...]" (PIOVEZANI, 2020, p. 9). Tal observação também é feita por Angenot, quando destaca que o objetivo da obra "[...] consiste em interpretar a formação e as metamorfoses de um extenso processo histórico de conservação de preconceitos e de depreciações sofridas pelas falas e pelas formas de escuta dos membros das classes populares [...]" (PIOVEZANI, 2020, p. 11).

Em sua Introdução, Piovezani narra uma cena do filme, Terra em transe (de 1967), do cineasta Glauber Rocha, quando um representante do povo da cidade fictícia de Eldorado, o sindicalista Jerônimo, tem sua boca tapada pelo jornalista Paulo, antes mesmo de começar a se pronunciar. Essa cena, segundo Piovezani, se repete há muito tempo, já que há consenso no imaginário social de que o povo não sabe falar nem escutar, pois "Os grupos dominantes acreditam e fazem acreditar que são detentores de uma maneira de dizer que é mais correta, culta e elegante do que a praticada por grupos dominados. Em consonância com os interesses dos primeiros, estes falariam e ouviriam melhor do que os últimos [...]" (PIOVEZANI, 2020, p. 17).

Ao longo da obra, Piovezani disseca essa afirmação, a começar com o primeiro capítulo - Ouvir a voz do povo -, em que ele vai tecendo uma historiografia sobre como a escuta se deu/dá enquanto construção histórica, considerando a implicação de fatores sociais, culturais, ideológicos e afetivos. Tais fatores, segundo ele, vão se materializar em práticas e discursos que produzem distinções do que se ouve, classificando os sons e as vozes em uma escala cujo ápice é o "sublime", passando pelo "agradável", pelo "incômodo" chegando, em último grau, ao "insuportável”. Nesse capítulo, o autor, para exemplificar sua questão, trata também de como os odores são historicamente constituídos como agradáveis ou não, além de tratar da questão da fala e do silêncio e sua relação com a condição humana.

No capítulo dois, Breve genealogia da voz e da escuta populares, ainda que o título aponte para uma "breve genealogia", o autor nos brinda com uma longa e cronológica (ainda que justificada) discussão visando a responder alguns questionamentos que ele levanta sobre a fala e a escuta do povo, são eles: 
desvalida e as que reclamam o reconhecimento da razão e da inteligência na voz do povo? (PIOVEZANI, 2020, p. 82).

Usando os cronônimos Antiguidade, Idade Média, Era Moderna, Modernidade e Contemporaneidade como guias - tendo em vista que, como ele aponta "[...] o que os homens pensam, dizem e fazem, possui uma historicidade que não se reduz a esses limites do tempo nem às fronteiras dos espaços que abrigam as ideias, as palavras e as ações humanos [...]" (PIOVEZANI, 2020, p. 83) - para mostrar como se dava a voz e escuta populares ao longo do tempo. Mas ressalva que no Brasil contemporâneo, as falas públicas da voz do povo adquiriram certo direito à existência.

Suas discussões perpassam pela retórica da Grécia e Roma Antigas, pela Igreja e a fala religiosa na Idade Média, pela emergência de uma eloquência popular na Idade Moderna, pela "invenção da igualdade" na Modernidade - que não respondeu "[...] à demanda de igualdade de condições sociais, econômicas e políticas entre sujeitos de classes e categorias distintas [...]" (PIOVEZANI, 2020, p. 109), chegando ao Brasil contemporâneo. Tal percurso aponta as modificações ocorridas na fala e escuta do povo e de seus representantes e as discriminações regularmente sofridas por elas - a fala e a escuta do povo.

Já no terceiro capítulo - Retratos de um porta-voz popular na mídia brasileira , o autor parte do pressuposto de que a produção e circulação desiguais dos discursos contribuem de forma decisiva para uma perpetuação do sequestro e difamação da voz e da escuta do povo. Piovezani se apoia nesse pressuposto para analisar o que se diz e como se fala dos usos da língua, do corpo e da voz de Luiz Inácio Lula da Silva em suas falas públicas como candidato à presidência, presidente e ex-presidente. Nesse capítulo, o autor identifica e interpreta discursos que tratam do desempenho oratório de Lula por meio da análise de enunciados e textos de distintos gêneros discursivos que foram produzidos pela mídia brasileira contemporânea e circularam em âmbito nacional. O que o autor constata é que, nesses três contextos, o verbo, $\mathrm{O}$ corpo e a voz "[...] do político mais popular da história brasileira [...]" (PIOVEZANI, 2020, p. 265) eram discriminados pela mídia, que se julga objetiva, mas que o deprecia e o ataca de forma crua e cruel, até mesmo pelos veículos midiáticos que se dizem progressistas.

Já em seu epílogo - Por uma metalinguagem da emancipação popular -, Piovezani apresenta uma alternativa para contornar o problema levantado ao longo 
da obra - a depreciação e deslegitimação da voz e escuta do povo - quando afirma que "Há casos em que a fala sobre a fala se mostra como ação libertadora e como instrumento privilegiado de libertação [...]" (PIOVEZANI, 2020, p. 269). Aqui o autor rememora três histórias nas quais, a seu ver, houve uma metalinguagem da emancipação popular ou das quais pode-se extrair uma perspectiva libertária, são elas: uma história envolvendo o então presidente Lula, em 2002; a candidatura de Felipe Poutou à presidência da França, em 2012, e parte da história de Caio Márcio, antes de se tornar o Coriolano, em 493 a. C. Ao trazer essas histórias, ele faz - ciente do lugar de onde fala, da ordem do seu discurso - a sua própria metalinguagem da emancipação popular, porque "Ele fala do que fora dito por outros, para tentar dar outros caminhos e sentidos ao povo." (PIOVEZANI, 2020, p. 294).

Em sua aula inaugural no Collège de France, Michel Foucault (2014, p. 9) afirmou que "Sabe-se bem que não se tem o direito de dizer tudo, que não se pode falar de tudo em qualquer circunstância, que qualquer um, enfim, não pode falar de qualquer coisa [...]". Piovezani (2020) bebe dessa fonte, mas também lhe acrescenta elementos de outras nascentes: ao postulado de Foucault segundo o qual "não é qualquer um que poder dizer qualquer coisa, em qualquer circunstância”, o autor de $A$ voz do povo acrescenta o fato de que esse dizer não pode ser formulado de qualquer maneira. Há a fala e a escuta de prestigio e há a fala e a escuta estigmatizada, e ele chama atenção para essa última, afirmando que o trajeto feito ao longo da obra só fará sentindo se houver uma "metalinguagem da emancipação popular" que só cumprirá seu destino se "[...] nos ajudar a compreender que as mulheres e os homens do povo pobre podem e devem se apoderar do discurso e dos efetivos exercícios de cidadania [...]" (PIOVEZANI, 2020, p. 34-35).

Dito isso, $A$ voz do povo é uma obra que traz à luz questões tão pertinentes para o contexto atual - de uma sociedade tão desigual (como pontua o professor José Luiz Fiorin na quarta capa da obra) -, e se faz leitura obrigatória para quem se interessa ou se preocupa em mudá-lo.

\section{Referências}

FOUCAULT, Michel. A ordem do discurso: aula inaugural no Collège de France, pronunciada em 2 de dezembro de 1970. Tradução de Laura Fraga de Almeida Sampaio. 24 ed. São Paulo: Edições Loyola, 2014. 